\title{
USE OF SATELLITE DATA IN MONITORING OF HYDROPHYSICAL PARAMETERS OF THE BALTIC SEA ENVIRONMENT
}

\author{
Adam Krężel, Ph. D. \\ Katarzyna Bradtke, Ph. D. \\ Agnieszka Herman, Assoc. Prof. \\ University of Gdańsk, Poland
}

\begin{abstract}
Intensive development of infrastructure for fast processing of outsized amount of space-borne data enables now to use the satellite data for operational controlling the state of its environment. In our presentation we show some examples of analysis of processes in marine environment which are possible due to satellite data and algorithms of its processing developed in SatBaltic Project. It concerns supporting of modelling of solar energy inflow to the sea with space-borne input data, identification and analysis of sea ice cover, supporting of oil spill detection, and identification of phenomena which modify spatial distribution of the sea surface temperature.
\end{abstract}

Keywords: satellite remote sensing, Baltic, SST, solar energy, sea ice, oil spill

\section{INTRODUCTION}

Systematic observations of the Earth environment from space started in the late seventies of the 20th century. Due to these data our knowledge about some environmental processes and phenomena has increased rapidly. It concerns both global processes and, in not smaller degree, local ones like, for instance, those occurring in the Baltic Sea. Fast development of infrastructure for efficient processing of the extensive amounts of data enables now to use the space-borne information for continuous, operational monitoring of the state of the environment.

Effective use of satellite data comprises two components. On the one hand, it requires new, complex algorithms that allow converting the electromagnetic signal registered by sensors onboard of the satellite to physically meaningful quantities characterizing the state of the environment. On the other hand, these new, specific information has to be incorporated into the analysis, which often had been limited or even impossible with the use of traditional sources of data. These were the assumptions on the basis of which the SatBaltic Operational System has been set up. Its main goal is to accomplish, in a possibly wide range, the above-indicated activities in relation to the Baltic Sea. In this work we show some selected examples of the application of the satellite data to the analysis of physical processes in marine environment, based on the algorithms created within the SatBaltic Project at the Institute of Oceanography, University of Gdańsk. In Section 1 we briefly present examples of particularly challenging and important groups of processes analyzed in the project: detection of clouds, oil spills and sea ice. The analysis of solar radiation and sea surface temperature (SST), shown in Section 2, demonstrates how the data obtained as a result of our algorithms can be applied in oceanographic research.

The presentation of the algorithms begins with those devoted to cloudiness. Among the components of the terrestrial atmosphere, cloudiness is the one that, with its high temporal and spatial variability, influences the solar irradiance at the sea surface to the highest degree. The solar irradiance at a given place depends on whether the Sun is obstructed by clouds totally, partly or not at all, and in what degree the clouds are transparent to the light. The related challenges lie not only in reliable estimation of the influence of clouds on the amount of solar radiation reaching the sea surface, but also in detecting totally cloudless regions, in which it is possible to determine such variables as SST or the surface chlorophyll concentration. Even small cloudmasking errors can result in serious errors in the analysis of these quantities.

Huge oil spills from oil platforms or tankers, being result of accidents, can seriously affect marine and coastal environment, but they are rare and relatively easy to detect. In the Baltic Sea, the main source of oil pollutants is illegal dumping of oily wastes from ships. Regular, small-scale spills, contribute to high overall amount of the hydrocarbons released to the environment, whose negative impact cannot be diminished [3]. They require frequent observation of large areas in order to identify as many events as possible. For this reason, the routine aerial surveillance nowadays is usually supported by the satellite SAR (Synthetic Aperture Radar) data. 
The third of the presented algorithm examples concerns sea ice, the monitoring of which has practical importance for marine transport and fishery, as well as weather forecasting, as sea ice is an important component of winter climate of the large parts of the Baltic Sea region. Experiments with a mesoscale Weather Research and Forecasting (WRF) model, performed in the SatBaltic project, suggest that the quality of sea ice data has significant influence on the simulated weather not only over the sea, but also the surrounding land.

\section{DEVELOPMENT OF ALGORITHMS FOR SPACE-BORNE DATA PROCESSING}

\section{CLOUDINESS}

During daytime, the simplest method of observation of cloudiness from space is based on the visible part of the spectrum where white clouds are easy noticeable on the background of a dark sea. There are several radiometers which can observe the Earth's colour from space [1] [10], but because of the high temporal dynamics of this phenomenon it is important to choose the source that provides data as frequently as possible - preferably devices working on geostationary satellites. The area of the Baltic Sea is located in the field of view of SEVIRI (Spinning Enhanced Visible and InfraRed Imager) working on board of Eumetsat's Meteosat Second Generation (MSG) satellite. It observes the Earth in 12 spectral channels and produces its image every 15 minutes. Basing on these data, it is possible to calculate "cloud fraction" that corresponds with the meteorological cloudiness, and "cloud transmission" which characterises the amount of solar radiation transmitted by clouds. Details of the algorithm are presented in [6]. In practice, the only alternative to such information is atmospheric modelling, but as one can see in Fig. 1, very often a good agreement in results at one time instance is followed by a total inconsistency at one time instance is followed by a total inconsistency at another. Independent measurements of solar radiation do not leave doubt which data are closer to reality.

As described in Section 2.1, SEVIRI provides the first, crucial component to the set of input data necessary to operate the solar energy transmission model. It enables calculation of the most important parameter which influences the majority of processes in marine environment.

\section{SUPPORT OF OIL SPILL DETECTION}

Oil spills may be detected in the SAR-C images because of the damping effect of the oil on the backscattered signals from the radar instrument. This local decrease of backscattered energy appears as a dark spot in the image.

SAR can collect data independently of weather and light conditions, what makes it an excellent tool to monitor illegal spillages. Before ENVISAT, European Space Agency's satellite which operated from 2002 to 2012, access to SAR data was limited due to their high costs. Currently, a similar instrument operates on the Sentinel 1 satellite.
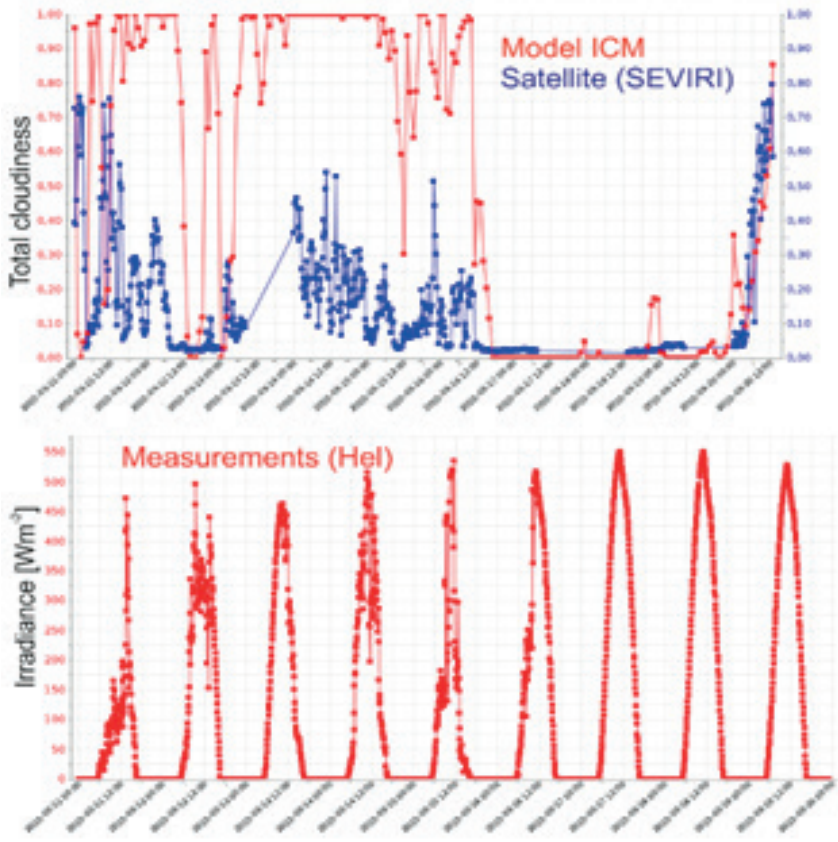

Fig. 1. Example nine days of variability of cloudiness observed from space and modelled (top) and solar irradiance measured (bottom) in the vicinity of Hel

The problem with interpretation of SAR data in the context of the oil pollution monitoring is the fact that oil spills are not the only phenomena causing dark spots in the images. Amongst phenomena causing misleading look alikes are also: grease ice, intensive algal blooms, windless areas known as "calm areas", or upwelling regions. To distinguish oil slicks from their look alikes, knowledge about their specific features and environmental conditions has to be taken into account. Thus, manual inspection of SAR images, by highly-qualified operators, is still the most popular technique. Operators use a software that can calculate some spot attributes, but they still have to go through the whole image manually. This is time consuming and many ideas for automation of this process have been proposed over time. Our team contribute to solve this problem [5].

The goal of our work, undertaken as a part of the SatBaltic Project, was to develop a methodology that would improve inspection of the SAR images. Particular emphasis was put on the adaptation to the specificity of the seas, like Baltic Sea, where small, elongated oil spillages take place due to shipping activities and their location is difficult to predict.

We proposed an object-oriented approach to the radar image interpretation using the ENVISAT ASAR (Advanced SAR) images and eCognition software for image interpretation (Fig. 2). The algorithm consist of four main steps: preprocessing of the data, hierarchical segmentation, dark spot recognition and their classification.

The algorithm utilizes a multi-resolution segmentation technique to obtain a hierarchy of objects at various scales. Such approach to the segmentation process enables to detect oil slicks, which vary in scales, and also to put dark objects in context of their surroundings defined by larger regions. The classification scheme is based on a 'decision tree' logic, which aims to eliminate look-alikes rather than classify all dark spots 
into categories. A number of aspects is taken into account in the classification process, e.g., the shape characteristics and contrast to the surroundings, or position relative to the land, major shipping routes and the neighbouring objects on the sea surface.
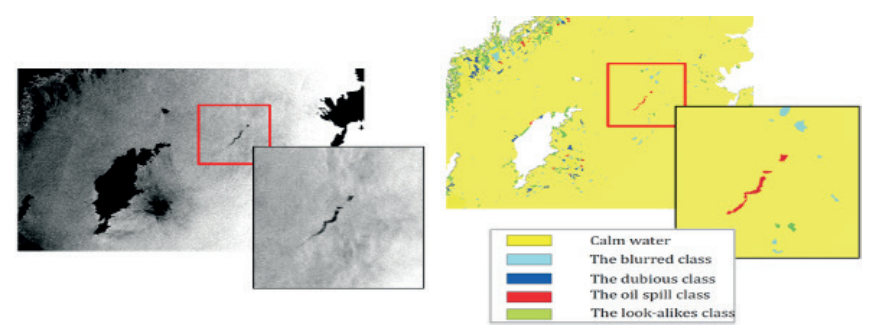

Fig. 2. Sample ASAR image with the confirmed oil spill (indicated in frames) and result of the algorithm - a classified image (source of data: ESA, ASAR WSM, VV, May 7, 2008)

The algorithm seems to be very reliable. Its performance was tested on a group of oil spills recorded by HELCOM. After automatic extraction of all dark spots from ASAR images and elimination of over $95 \%$ of them as look-alikes, over $95 \%$ of known oil spills has been successfully identified. We plan to improve and adapt this algorithm for Sentinel-1 data, and to run it in operational mode in the nearest future.

\section{SEA ICE}

Many challenges related to the satellite monitoring of sea ice are common with those that accompany determining other sea/land surface characteristics (e.g., lack of data in cloud-covered regions in visible imagery, or limited space/ time data coverage in ASAR data [7]). Other are specifically related to sea ice properties. In order to fully characterize the state of the sea ice cover in a given area, a number of such properties have to be measured, including ice concentration (fraction of the sea surface covered with ice), thickness distribution, floe-size distribution, ice age and type (level ice, frazil ice, deformed ice etc.; Fig. 3), albedo, snow-cover thickness, velocity, temperature, and so on. Many of these properties are strongly scale-dependent, i.e., they change with changes of the resolution of observation/analysis, which makes comparisons of results obtained with different methods difficult if not impossible.

Whereas satellite sea ice monitoring is difficult in general, it is particularly challenging in the case of seasonal sea ice, which is thin, has relatively low albedo and high temperature (in the early phases of freezing close to the albedo and temperature of the surrounding sea water), and due to its low mechanical strength is easily deformed and broken during storm periods and susceptible to fast melting under favourable conditions. Consequently, the state of the ice cover may change rapidly in periods with strong wind and/or air temperature variability. These events - interesting scientifically and important from the point of view of marine transport and weather prediction in affected areas - pose a particularly demanding test for satellite algorithms and expose their limitations. A storm over the northern Baltic Sea in early March 2010 provides a good example (Fig. 4). Under strong westerly winds associated with a fast-moving low-pressure system, the hitherto compact ice cover in the Gulf of Bothnia broke up and drifted to the east, leaving large areas of open water in the western parts of the basin (Fig. 4d, h). This significant change is resolved neither in the low-resolution $\left(1^{\circ}\right)$ Global Forecasting System (GFS) dataset (Fig. 4a, e), nor in the Group for High Resolution SST (GHRSST) dataset dedicated to the Baltic Sea (Fig. 8b, f; resolution $0.03^{\circ}$ ) - both popular products with several applications, e.g., in numerical modelling. In both cases the sea ice extent after the storm is hardly different from that before the event. The results of the algorithm developed as part of the SatBaltic project (Fig. 4c, g) are much more realistic. The algorithm (suitable for operational use) produces daily maps of sea ice extent based on the whole set of SEVIRI data from a given day, i.e., 96 maps (available every 15 minutes) from 3 visible (VIS) and 4 infrared (IR) channels. This enables to reduce the number of gaps in the final product, because, first, all pixels that have been cloudless even during a very short time during a day are included in the analysis, and second, the time-variability of values from a given pixel can be used as an indicator of the presence of clouds. The core of the algorithm, which performs the essential classification of the data into 3 classes (water, clouds, and ice), operates on the VIS data; at further stages, correction to the initial results is performed based on the IR data in order to improve detection of thin, low-albedo ice. Importantly, each sea ice map is produced from the previous one by actualizing the values of those pixels that could be identified as either water or ice; in other words, the final products are not updated in permanently cloud-covered regions.

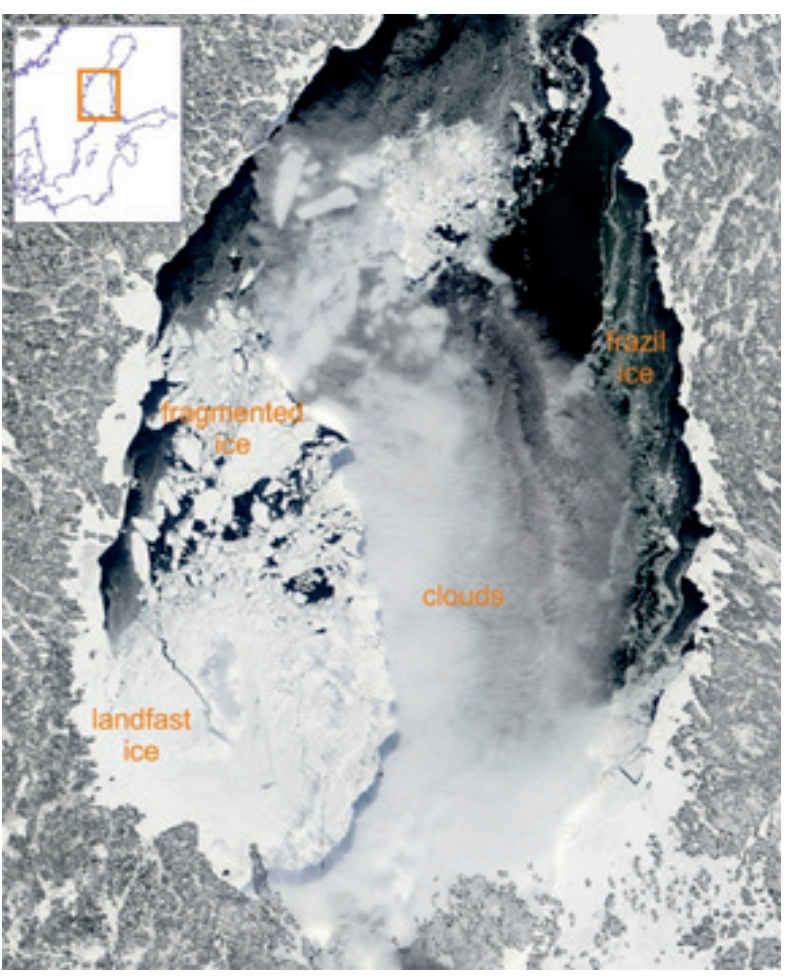

Fig. 3. Fragment of a MODIS Terra image of the Gulf of Bothnia from March 3, 2010 

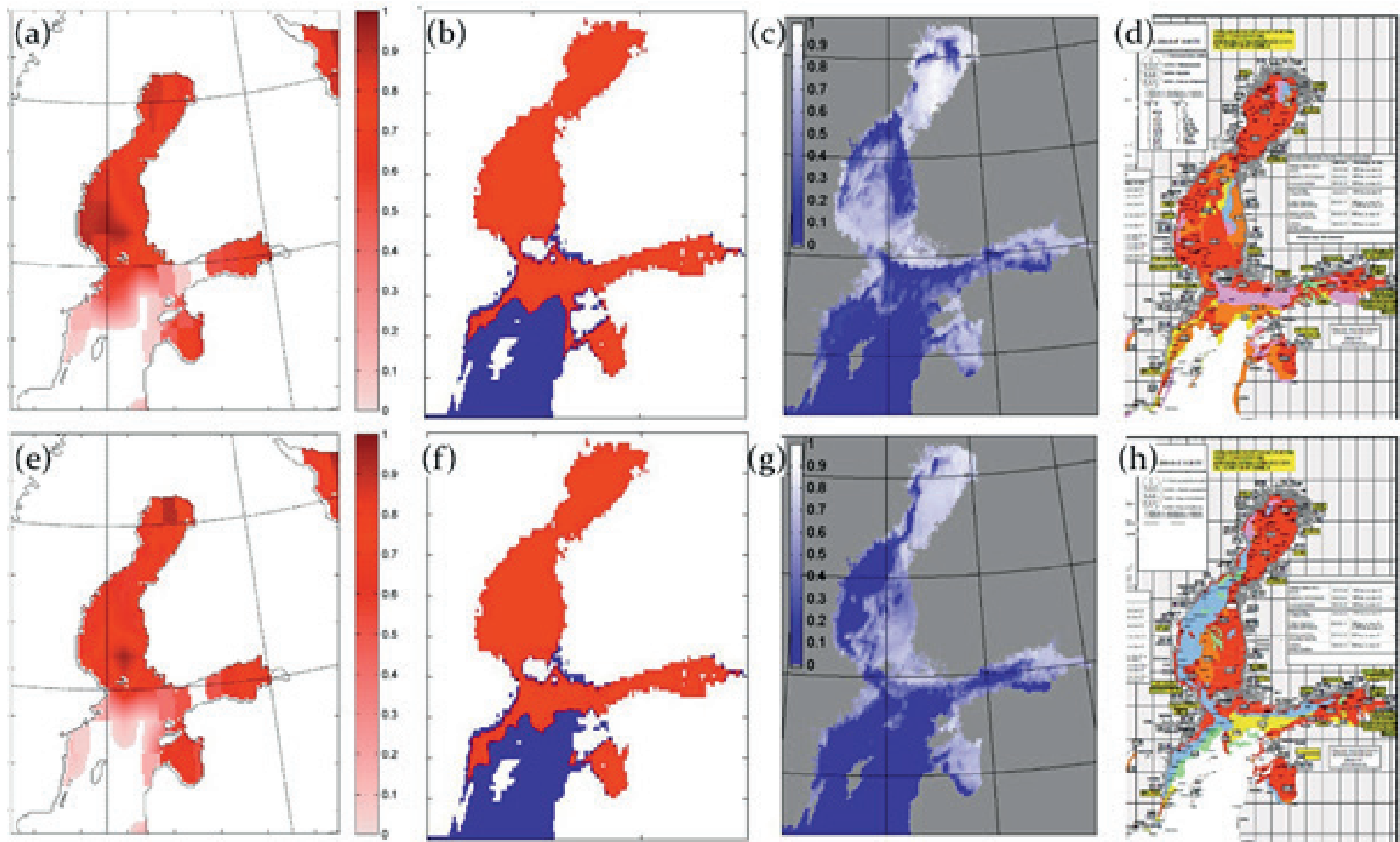

Fig. 4. Examples of satellite sea ice products $(a-c, e-g)$ and SMHI ice charts $(d, h)$ for the Baltic Sea, showing situation before and after a storm in March 2010 ( $a$-d: 7th March, e-h: 12th March). GFS sea ice concentration $(a, e)$, GHRSST sea ice extent $(b, f)$, SatBaltic sea ice albedo in the High Resolution Visible (HRV) channel $(c, g)$

Cross-validation with other sea ice products from the period 2010-2014 (not shown), as well as analysis of selected cases like the one presented above, confirm reliability and accuracy of the method, but also reveal its main limitation. Namely, in December and January - periods with short daytime and persistent cloudiness over the northern Baltic Sea - the average time interval between subsequent updates of the maps over the Gulf of Bothnia equals 5 days (as compared to 1.5-2 days in March and 0.5-1 day in April). Hence, although the SEVIRI-based algorithm is very attractive (apart from the ice extent and albedo, it provides a possibility to determine the temperature of the ice surface), it illustrates the need for combining data from many different sources in order to obtain sea ice information sufficiently complete in space and time.

\section{APPLICATION OF SATELLITE DATA IN ANALYSIS OF THE ENVIRONMENT}

\subsection{SOLAR ENERGY}

The amount of solar energy reaching a given place at sea surface depends on the position of its source (solar zenith angle) and the state of Earth's atmosphere in terms of its components that influence solar radiation transmission on the way from its upper boundary. The amount of solar energy can be determined by means of direct measurements or calculations with the use of various models of different precision and complexity. Both measurements and calculations, are particularly complicated over the sea area due to problems with the exact information about the main components of the atmosphere. In the case of models, their accuracy can be improved by use of information from space. In the simplest way, the solar irradiance at the sea surface $\mathrm{E}_{\mathrm{s}}(\lambda)$ can be expressed as:

$$
E_{s}(\lambda)=\cos \vartheta \frac{F_{s}}{\beta^{2}} T(\lambda)
$$

where: $\lambda$ denotes the wavelength; $\vartheta$ - the solar zenith angle, $\operatorname{Fs}(\lambda)$ - the spectral density of the solar constant; $\beta=R s / R-$ the factor defining the annual variability of the distance between the Earth and the Sun ( $R$ and $R_{s}$ - actual and mean distance between the Earth and the Sun, respectively) and T transmission function depending on all important processes of light attenuation in the atmosphere. It can be expressed in the form of the product:

$$
T(\lambda)=T_{R}(\lambda) T_{a}(\lambda) T_{O_{3}}(\lambda) T_{w v}(\lambda) T_{G}(\lambda) T_{c l}
$$

where subscripts $\mathrm{R}, \mathrm{a}, \mathrm{O}_{3}, \mathrm{wv}, \mathrm{G}$ and cl denote dependency on molecular scattering, attenuation by aerosols, absorption by ozone, water vapour and other atmospheric gases, and attenuation by cloudiness, respectively. Optimal forms of some transmission functions in equation (2) can be worked out on the basis of space-borne data about such variables as cloudiness, aerosol optical thickness or ozone and water vapour content in the atmosphere [4]. Below, we present results of model calculations in which some input data were replaced by space-borne source. 
Cloud transmittance was calculated based on measurements taken in channel 12 (HRV) of SEVIRI. It has spatial resolution of $1 \mathrm{~km}$ in the sub-satellite point, recalculated for Baltic to a $4-\mathrm{km}$ grid. The map in Fig. 5 presents the mean diurnal cloud transmission. The ultimate result of the calculations, i.e., the daily dose of solar energy at the sea surface, shown later, was obtained as a sum of the SEVIRI data available every 15 minutes.

\section{AEROSOLS}

From the point of view of the solar radiation transmission, aerosols are the second-important component of the atmosphere. Due to their impact on light, their monitoring from space is performed in a visible part of the spectrum, which means that is possible only in the daytime and in cloudless areas. Standard algorithms used to determine the aerosol optical thickness (AOT) are based on data from a single spectral channel of the AVHRR (Advanced Very High Resolution Radiometer) [9]. The data of AOT that are used to determine $\mathrm{Ta}$ (eq. 2 ) are operationally archived by NOAA CLASS (Comprehensive Large Array-data Stewardship System) based on one week's worth of data. Their spatial resolution is $100 \mathrm{~km}$. An example of this product for the Baltic Sea is shown in Fig. 6.

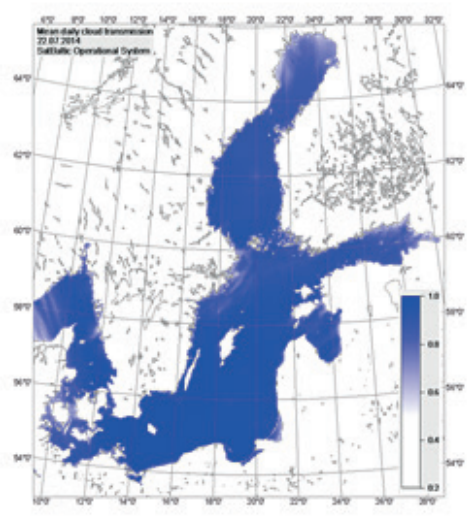

Fig.5. Mean daily cloud transmission at July 22, 2014 on the basis of SEVIRI data

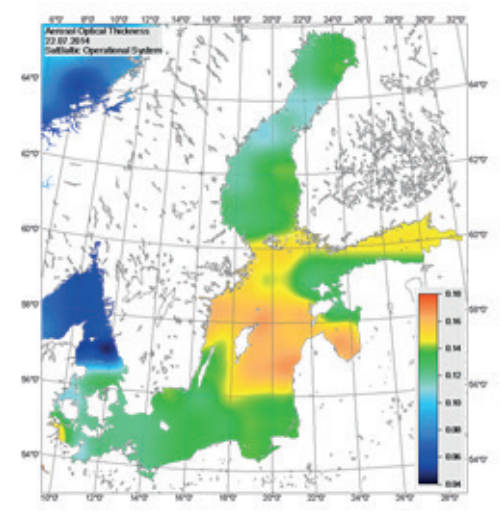

Fig. 6. Aerosol optical thickness on July 22, 2014 on the basis of AVHRR data
Absorption of solar radiation by ozone has a crucial importance for life on our planet. In standard conditions, its role consists in cutting off the UV-wavelength below 280 $\mathrm{nm}$. For the total solar radiation at the sea level, absorption by ozone has minor importance. Nevertheless, the use of space-borne ozone information for determination of $\mathrm{T}_{\mathrm{O} 3}$ in the model of light transmission in the atmosphere makes calculations more reliable. Satellite remote sensing of the total ozone in both the stratosphere and troposphere is based mainly on measurements of the ultraviolet albedo of the Earth. An example in Fig. 7 presents the results of analysis made within the framework of TOAST (Total Ozone Analysis using SBUV/2 - Solar Backscatter UltraViolet Version2 and TOVS - Tiros-N Operational Vertical Sounder). It produces total column ozone in the troposphere and lower stratosphere on the basis of measurements in the UV-range, made by SBUV/2 instrument and in infrared in mid-to-upper stratosphere by TOVS.

\section{SOLAR ENERGY FLUXES AT THE SEA SURFACE}

The above-mentioned continuous observations of the Earth's environment from space provide self-contained information about state of the terrestrial atmosphere. The knowledge obtained in this way makes the results of atmospheric modelling much more reliable, particularly when instantaneous, short-time results are of interest. A good example of information which can be obtained in that way is spatial distribution of photosynthetically active radiation (PAR). Beside the SST and the surface chlorophyll concentration, it is desirable to calculate intensity of such complex and important processes like the primary organicmatter production and the photosynthetically released oxygen in the water. An example result of the PAR calculation with a model working as a part of the SatBaltic Operational System [11] is presented in Fig. 8. An assessment of the accuracy of the model in regard to in situ measurements at the Hel station showed an increase of the linear correlation between the modelled and measured values from 0.87 to 0.94 when non-satellite input data were substituted by space-borne ones.

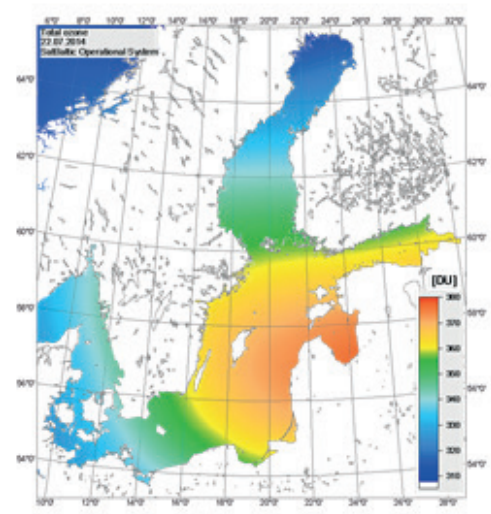

Fig. 7. Total column ozone in the atmosphere over Baltic Sea at July 22, 2014 on the basis of TOAST analysis (values in Dobson units) 


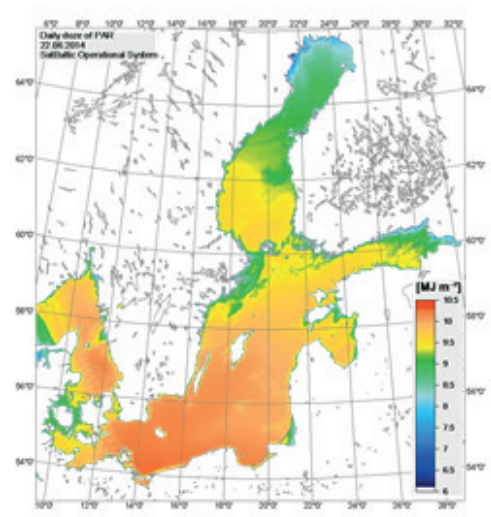

Fig. 8. Example of daily sum of photosynthetically active radiation at the sea surface at July 22, 2014 calculated within SatBaltic Operational System

\section{SPATIAL DISTRIBUTION OF THE SEA SURFACE TEMPERATURE}

There were many radiometers providing SST data over the history of environmental remote sensing. One of them is the AVHRR radiometer operating since 1978 on board a series of American NOAA satellites and now also on the European METOP -A and -B. Its three thermal infra-red bands let to estimate SST in clear-sky conditions with errors less than $1 \mathrm{~K}$ and a resolution of $1 \mathrm{~km}$.

In the Baltic Sea area, frequent cloudiness often partially or entirely precludes the use of satellite sensors for recording radiation leaving the sea surface in the thermal infra-red bands. Thus, precise algorithms for detection of cloudiness, as well as ice cover, are required to mask areas where SST estimation is not possible. Despite this limitation, nowadays, by combining historical satellite data derived from different radiometers (AVHRR, MODIS, SEVIRI, etc.) we have access to huge database suitable for analysis of long-term changes in SST. In situ data, of course, provide longer time series of water temperature observations, but they are usually limited to the few coastal monitoring stations. Satellite data enable to study spatial variations of the climate change effects (Fig.9).

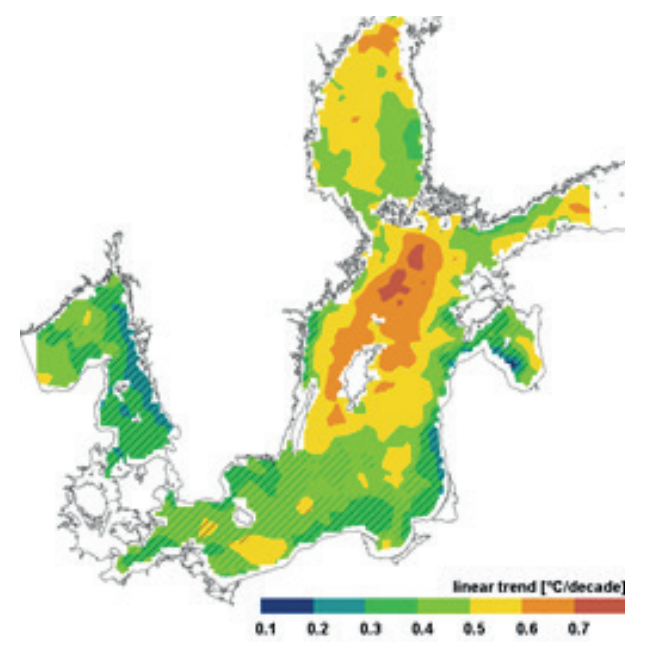

Fig. 9. Linear trends of the annual mean SST in the period 1986-2005 based on AVHRR and MODIS data from PO.DAAC (Physical Oceanography Distributed Active Archive Center) database
The general utility of the satellite data is even more apparent in studies of episodic phenomena such as upwelling currents or spreading of fresh-water inflows.

Coastal upwellings in the Baltic Sea [8] brings water from below the thermocline to the surface, where it mixes with the upper-layer waters. During summer and autumn, when the sea surface is warm, upwelling is seen on infrared satellite im

ages as a local drop in temperature up to several degrees. Thermal fronts derived from SST maps show spatial scale of this phenomenon and its development in time (Fig. 10).

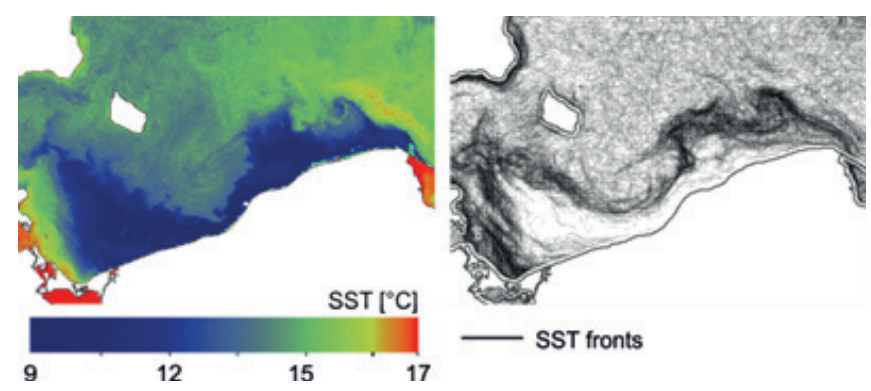

Fig. 10. Example of SST distribution (AVHRR June 30, 2008) with evidence of a coastal upwelling event along the Polish coast and location of thermal fronts determined on the basis of a gradient analysis on a sequence of images collected during 7 days

In the southern part of the Baltic, rivers bring to the sea a lot of suspension and dissolved organic matter, which influence the transparency of sea water. Due to the high dynamics of riverine plumes, investigation of the extent of offshore penetration of the fluvial waters is difficult. However, they usually differ from seawater in temperature, especially in spring and autumn, when inflow is also the highest. This fact enables us to use thermal radiometers for investigation of the extent of offshore penetration of the riverine waters. It gives contemporary information to maps of optical parameters (e.g. diffuse light attenuation coefficient Kd in Fig. 11) derived from ocean colour data, which are limited to daily observations (Fig.11).

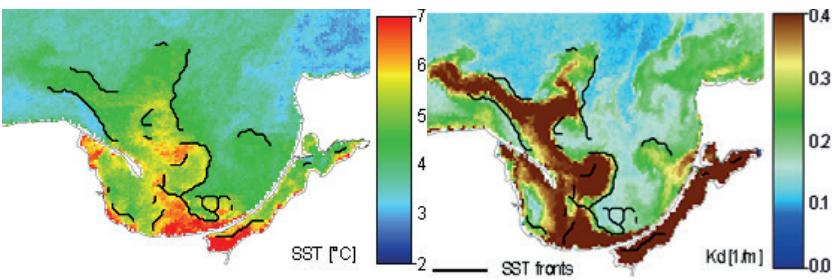

Fig. 11. Example of SST distribution with evidence of the fresh water inflow from the Vistula River and collocation of thermal fronts with spatial distribution of turbid waters (MODIS April 1, 2005)

\section{CONCLUSION}

The problems presented in this paper demonstrate, on the one hand, an immense potential to increase our knowledge about environment if observed from space, and on the other hand, how much can be done yet in that matter. The examples shown were often based on data recorded by "classic" satellite 
radiometers (AVHRR, MODIS, ASAR, SEVIRI). Some of them (ASAR/ENVISAT) have already ended their activity, others, for example MODIS, are approaching the end of their longstanding missions. Nevertheless, the very positive experience with them results in preparing new missions. One of them, in which our group is engaged, is a family of ESA's missions called Sentinels [2]. Its first member, Sentinel 1, was launched on April 3, 2014. Its activity gives us an opportunity to remove at least some of the problems related, e.g., to sea ice monitoring (our sea-ice algorithm based on archival ASAR data gave very promising results). The next one, Sentinel 3 which should start this year is a multi-instrument mission to measure sea-surface topography, sea- and land-surface temperature, ocean colour and land colour with high-end accuracy and reliability. Another one, Sentinel 4, is a payload devoted to atmospheric monitoring that will be embarked upon a Meteosat Third Generation-Sounder (MTG-S) satellite in geostationary orbit.

This is only a small example of the very fast development of the Earth observing system; it shows that every activity leading to the development of infrastructure suitable to process the ever-increasing amounts of data is justified and still needed. It can guarantee a better knowledge of phenomena and processes that occur in the ever faster changing environment, and give us a chance of better understanding the surrounding world.

\section{ACKNOWLEDGEMENT}

This work was supported by the European Union through the European Regional Development Fund Project Satellite Monitoring of the Baltic Sea Environment (SatBaltyk) POIG 01.01.02-22-011/09 and DS/530-G210-D425-14.

\section{REFERENCES}

1. S.A. Ackerman, K.I. Strabala, W.P. Menzel, R.A. Frey, C.C. Moeller, L.E. Gumley, Discriminating clear sky from clouds with MODIS, J. Geophys. Res., 103, D24, (1998),32,141-32,157.

2. European autonomy in space, C. Al-Ekabi (ed.), Springer International Publishing, (2015), 198.

3. J. Fabisiak: Ecological risks associated with chemical pollution of the Baltic Sea - hydrocarbons, (in Polish), Zeszyty Naukowe Marynarki Wojennej, XLIX, 3 (174), (2008), 7-24.

4. M. Konik, K. Bradtke: Characteristics of the oil spills detected in the Baltic Sea area in ENVISAT ASAR Images, Earth observation for ocean-atmosphere interactions science, Conference, 28-31.10.(2014), Frascati (Italy).

5. A. Krężel, K. Bradtke: Estimation of solar energy influx to the sea in the light of fast satellite technique development, in Rugescu Radu ed., Solar Power, Rijeka, InTech, (2012), ch. 10, pp. 171-192.
6. A. Krężel, Ł. Kozłowski, M. Paszkuta: A simple model of light transmission through the atmosphere over the Baltic Sea utilising satellite data, Oceanologia, 50 (2), (2008), 125-146.

7. A. Mazur, A. Krężel: Object-based classification of Baltic Sea ice extent and concentration in winter, J. Earth Sci. Engng, 2, (2011), 488-495.

8. K. Myrberg, O. Andrejev, Main upwelling regions in the Baltic Sea - a statistical analysis based on threedimensional modelling, Boreal Environment Research, 8, (2003), 97-112.

9. L.L. Stowe., A.M. Ignatov, R.R. Singh: Development, validation, and potential enhancements to the secondgeneration operational aerosol product at the National Environmental Satellite, Data, and Information Service of the National Oceanic and Atmospheric Administration, J. Geophys. Res., 102, D14, (1997), 16923-16934.

10. M.J. Uddstrom, W.R. Gray, Satellite cloud classification and rain-rate estimation using multispectral radiances and measures of spatial texture. J. Appl. Met., 35: (1996), 839-858.

11. B. Woźniak, K. Bradtke, M. Darecki, J. Dera, J. Dudzińska-Nowak, L. Dzierzbicka-Głowacka, D. Ficek, K. Furmańczyk, M. Kowalewski, A. Krężel, R. Majchrowski, M. Ostrowska, M. Paszkuta, J. Stoń-Egiert, M. Stramska, T. Zapadka: SatBałtyk - A Baltic environmental satellite remote sensing system - an ongoing project in Poland. Part 1: Assumptions, scope and operating range, Oceanologia, 53 (4), (2011), 897-924.

\section{CONTACT WITH AUTHOR}

\author{
Adam Krężel \\ Katarzyna Bradtke \\ Agnieszka Herman \\ Institute of Oceanography \\ University of Gdańsk \\ Marszałka Piłsudskiego 46 Ave. \\ 81-378 Gdynia \\ Poland
}

e-mail: oceak@ug.edu.pl 